\title{
A IDEOLOGIA DA "NEW ECONOMIC HISTORY"
}

Josemir Camilo *

A "Nova História Econômica" (New Economic History) se apresenta como uma metodologiá aplicada à pesquisa histórica em áreas onde métodos tradicionais não tém conseguido bons resultados. Sua principal caracteristica está no uso da matemática e dos computadores.

Nascida praticamente da Escola de Chicago, a "Nova História Econômica"' é uma síntese de História, Economia, Estatistica e Filosofia. Busca obter, a nível teórico, respostas satisfatórias aos problemas econômicos em várias sociedades concretas. Geralmente, a área de aplicação desta metodologia é a de transporte e a de escravos, como o ilustram as obras de Fogel, Coatsworth e O'Brien. ${ }^{1}$ Aliás, o trabalho teórico deste último serve-nos de base para este artigo.

Os conceitos básicos desta "escola" são: Economia Social, Método Contrafactual e Conexões de Produção. ${ }^{2}$ A despeito de todo instrumental moderno e, aparentemente, com novos conceitos, a "Nova História Econômica" está cheia de controvérsias. A primeira delas é ideológica, haja visto sua metodologia vir sendo aplicada exclusivamente a sociedades capitalistas ou, quando muito, a socledades pré-industriais, porém dependentes do capitalismo, como é o caso da Rússia czarista. Além de que seu aparato conceptual decorre da teoria econômica clássica. Esta tendếncia está explicitada em O'Brien: "Alternativamente, a Nova História Econômica tem suprido respostas para espécies de circunscritas questōes em que os instrumentos da teoria econômica em geral, e neo-clássica em particular, podem ser usados com máximo efeito". 3

O ponto de partida desta Escola é a premissa de que um pequeno grupo

- Professor do Departamento de Sociologia e Antropologia da Universidade Federal da Parafba, Campus II - Campina Grande, atualmente em Curso de Pós-Graduação no London School of Economics, Londres, Inglaterra.

(1) O'BRIEN, Patrick: The New Economic History of the Railways, London, Groom Helm, 1977. COATSWORTH, John H.: Growth Against Development (The Economic Impact of Railroads in Porfiriam Mexico, lllinois, Northern Illinos University Press, 1981). Essa obra é uma tradução revisada, com nova Introduçăo, do original em espanhol "Crecimiento contra Desarrollo".

(2) Os termos precisos da "Nova História Econômica" em inglês são: socia/ saving, counterfactual ana/ysis e linkages (backward and forward). Tentamos aqui uma tradução aproximada desses conceitos. Porém as traduções de conceltos freqüentemente apresentam cificuldades mals ou menos graves. Por exemplo: talvez a melhor tradução para social saving fosse "poupança social", enquento para linkages provavelmente "conexōes (de produção) " seja mais adequado do que o termo literal de "ligações"

(3) O'BRIEN, Patrick: op. cit., p. 18.

\begin{tabular}{|l|l|l|l|l|l|}
\hline Rev. RAIZES & Campina Grande & Ano II & No $2-3$ & $177-181$ & jan.-dez./1983 \\
\hline
\end{tabular}


de países da Europa Ocidental, América do Norte e Austrália têm tido um crescimento econômico mais rápido que os outros paŕses. Seus autores não se referem - de modo algum - a experiências em países socialistas, tanto sobre crescimento económico, quanto à aplicação de sua metodologia. Não se dão conta, pois, que andam estudando determinado modo de produção: o capitalista. E é aqui, ainda, que reside sua falta de perspectiva como Historiadores: não discutem a Acumulação Primitiva do Capital; partem, já, da sociedade capitalista estabelecida como tal.

Para a "Nova História Econômica" não interessa saber como se adquiriu o capital. Parte-se diretamente de sua existência e de que, segundo O'Brien, "... mais altas taxas de crescimento podem vir também de mais terra, trabalho, capital, educação e organização para produzir output" ${ }^{.4}$ Como se depreende da leitura, trata-se de uma definição mais própria de um economista de que um historiador, porque se nega, justamente, o processo de gênese não só do capital em si, mas também das relações de produção que são o capital em reprodução. Em outras palavras, para a "Nova História Econômica" não há história mas sim contemporaneidade.

Tal tipo de raciocínio vem desembocar numa espécie de sofisticado estruturalismo, uma vez que um dos procedimentos desta Escola é a escolha dos inputs a serem quantificados. A priori, selecionam-se os inputs que irão formar uma estrutura e, em seguida, recorre-se ao método comparativo confrontando as estruturas montadas com material historiográfico àquelas feitas através de um mito chamado método contrafactual. Para nós, detecta-se aqui uma redução da História a uma pré-fabricada armação teórica.

O método (ou análise) contrafactual é uma falsa proposição em História. Baseia-se no hipotético argumento de contrapor os fatos históricos à sua nãoexistência. Ou seja: analisam certa sociedade e seu crescimento econômico, partindo da suposição do que seria se ela não possuisse os meios de transporte que tem historicamente possuído. Assim, por exemplo, se indaga: como seria a economia do Nordesta brasileiro se não tivesse havido ferrovias? Ou melhor: as ferrovias foram fator de crescimento econômico, haja visto que os cálculos feitos sobre os outros meios de transporte, competitivos às ferrovias, possuíam custo operacional bem mais al to? Não só é feita esta comparação, a qual necessariamente não utiliza a análise contrafactual, mas a solução que aponta as ferrovias como fator preponderante de desenvolvimento, passando primeiro por esta etapa (a comparação de duas estruturas existentes) e, em seguida, pelo seguinte raclocinio: que custo de operação teriam aqueles meios de comunicação, competitivos às ferrovias, se estas não existissem? É al onde reside o exercicio metaffsico da "Nova História Econômica".

O caráter da análise contrafactual é metafísico na medida em que isola duas estruturas e as torna absolutas, sendo que uma delas é totalmente hipotéti-

(4) Idem, p. 16. 
ca. Trata-se de um estruturalismo contraditório, pois ao mesmo tempo é funcionalista, usa de raciocínio abstrato-hipotético, caindo na metafísica. É funcionalista ao seccionar a História em categorias estanques, fazendo delas estruturas aprioristicamente determinadas, através das quais giraria todo o processo histórico ferroviário, no particular, e o econômico-social, no geral.

Convém ainda lembrar que o fato de criar (hipoteticamente) uma estrutura (a nãoexistência de ferrovias numa sociedade que, historicamente, sempre as utilizou), é uma volta ao empiricismo grotesco, como se as Ciências Sociais, e mais particularmente a História, comportassem experiências, ou experimentos dessa natureza. 5

Deve-se destacar bem que a análise contrafactual tornou-se o fulcro das dissidéncias da Escola. O percuciente trabalho teórico de O'Brien faz restrições também ao uso dessas mirabolantes hipóteses, embora não as condene com veemência. Seu emprego fica limitado aos economistas Fogel, Fishlow, Menzer e Hawke, célebres teóricos da Escola.

Uma vez repudiada a análise contrafactual, o conceito de "economia social" se esvazia. Segundo O'Brien, . "economia social" é "a diferença entre o atual custo de transporte ferroviário, em determinado ano, e o custo alternativo para transportar os mesmos bens, entre os mesmos pontos, sem ferrovia". 6 Portanto, trata-se de um exercicio matemático-estatístico, baseado nas hipóteses apontadas. Como um silogismo, se se aceita a premissa da "economia social", a da análise contrafactual será também aceita (não tanto quanto ao resultado, mas quanto a seu usol.

O virtuosismo destes economistas chega ao ponto - como em Fishlow, Hawke e Metzer (segundo 1 $O^{\prime} B$ rien)' - de não admitirem na sociedade nenhuma mudança, negativa ou positiva, durante o ano tomado como referéncia para a aplicação da análise contrafactual. Estamos diante de uma metafísica imobilista, servindo a um novo tipo de empiricismo: a experiência abstrata, de forte vocação especulativa.

Ora, qualquer setor da produção que seja anulado (teoricamente) ou que haja parado de produzir, no perfodo de um ano, dentro de uma sociedade, nâo implica necessariamente em colapso de uma economia. Os investimentos podem ser dirigidos a outros setores que não aqueles que formam os meios de comunicação alternativos. Querer comparar os custos de transportes, deixando de lado as ferrovias, é totalmente arbitrário. Assim, no Brasil, o governo pode optar (historicamente falando) por uma polittica de colonização rural, como fez com os flagelados da seca de 1877 (que foram para Pernambuco e Alagoas), ou mesmo incentivar a pequena indústria de bens de consumo. Isto, claro, partindo do

(5) Nesta perspectiva, a crítica de J. Coatsworth é bem procedente, apesar de ele pertencer a Escola. Coatsworth, op. cit. pp. 194-5.

(6) O'BRIEN, Patrick: op. cit., p. 31 e COATSWORTH, John H.: op. cit., pp. $10-11$. 
raciocínio de haver a ferrovia parado de operar. No caso, então, de a ferrovia estar em pleno funcionamento, a análise contrafactual peca por relegar - de modo absolu to - a realidade concreta que são as relações de produção (no caso, interligada, dependente ou hegemônica), às ferrovias.

Desta maneira, ignorando a História Social (das relações de produção), a "Nova História Econômica" introduz a ideologia de uma sociedade monolítica e sem diferenças de classes, principalmente através do seu conceito de "economia social". Para esta Escola, "economia social" é a economia de recursos, a qual é obtida com inovação tecnológica. No caso das ferrovias, seria o transporte mais barato comparado aos outros meios. Mas em nenhum momento estes autores se perguntam para quem, realmente, vão os benefícios ou lucros desse transporte mais barato. É al onde a ideologia se revela.

Para se chegar ao conhecimento desta economia de recursos, os historiadores deveriam estimar o output da ferrovia "em unidades de toneladas $/ \mathrm{mi}$ thas de frete carregado nos trens sobre um ano". ${ }^{7} \mathrm{O}$ average seria obtido ao se comparar estes outputs com outras formas de transporte. Mas, nem todos os integrantes dessa escola concordam com esses argumentos. O'Brien acha que o output transportado pelas ferrovias não parece ser satisfatório para estes cálculos e os dados para medir o frete transportado em outros meios de comunicação, podem não ser tão representativos. imagine-se, então, o historiador generalizar para todo um período a partir apenas do average de um ano e em dados não tăo precisosI Não há base lógica para as escolhas entre os resultados. ${ }^{8}$

Revestindo-se de uma eclética liguagem que vai da História à Informática, passando pela Estatística, estes economistas alteram superficialmente os conceitos, pois permanecem dentro dos cânones da teoria clássica na explicação do capitalismo. Por exemplo: não analisam a inovação tecnológica enquanto fator de obtenção de mais-valia relativa, fonte de lucros para os capitalistas das ferrovias. Em contrapartida, criam o conceito de "economia social" - sob o qual escondem o caráter da apropriaçăo do lucro, preferindo pregar a presunta existência de certo "benefício social" (social benefits), Evitam falar de "lucros" (profits), preferindo o vazio conceito de "beneficios".

Coerentes com a mistificação dos conceitos, estes autores, que fazem economia retrospectiva e não História Econômica, terminam encarando a sociedade sob um prisma holista, sem classes, e provavelmente, sem conflitos de classes. Ou seja, escapa-Ihes a parte polftica do processo econômico-social. Isto revela seu caráter ideológico, tendenciosamente burguês. Na verdade, mesmo como exercício matemáticoestatístico, a metodologia da "Nova História Econômica" revela-se empiricista ao tratar de microeconomia. Sua cientificidade não pode ser comprovada a nível macroeconômico. O próprio $O^{\prime} B$ rien reconhece a

(7) O'BRIEN, Patrick: op. cit., p. 24.

(8) Idem, pp. 38-39. 
fragilidade dos vôos teóricos da Escola: "nem teoria nem estatística são provavelmente indicados para resolver disputas sobre uma razoável ou plausível taxa de mudança social", sendo que "historiadores podem agora ser tentados a concluir que a eficiência da escravidão e seu impacto sobre o crescimento dos estados sulistas na América (do Norte; J.C.) provavelmente, ao fim, não é reduzivel a proposições testáveis que possam ser conceituadas e pesadas dentro da armação da economia neo-clássica".9

A preocupação da "Nova História Econômica" está diretamente comprometida com o modo de produç̃o capitalista, uma vez que seus estudos se voltam para a verificação do impacto de certos meios de transporte (canais, ferrovias) sobre o crescimento da economia. Crescimento é a palavra chave: a influência das ferrovias sobre o Produto Nacional Bruto é que interessa à Escola e, dal, nasce o conceito da "conexäo" (linkage).

Que influéncia causou a ferrovia na economia regional? Como medir a produão de outputs gerados pela ferrovia e os inputs de que ela se utilizou? A resposta' está na aplicação da análise quantitativa contrafactual. E medir os inputs tanto da ferrovia, como dos outros meios de transporte, como se a ferrovia não tivesse existido. O mesmo para com os outputs. Neste caso "a margem de taxa de retorno sobre o capital investido em ferrovias sobre um único ano diz multo pouco sobre a importâncla global". 10

Alguns autores afirmam que mesmo não se aceitando estes resultados como prova da influência da ferrovia sobre o crescimento econômico, no mínimo, ter-se-ia comprovado que os investimentos em ferrovias têm apoiado a economla capitalista em perfodos de recessão. Portanto, cada vez mais se restringe o campo dos resultados ditos satisfatórios da "Nova História Econômica.".

Por fim, estes-supostos historiadores ignoram uma realidade histórica bastante desabonante de seus resultados: as ferrovias européias, construldas em paises do terceiro mundo. Camuflam completamente o fato da extração de mais-valia que as ferrovias têm obtido nos países de economia dependente. Esquecem que as estradas de ferro sấo produtos diretos da revolução industrial, principalmente no setor da siderurgia, e que os investimentos nas colônias ou regiôes de economia dependente (Brasil, no caso) só aconteceram depois de ter-se fechado o mercado europeu. As ferrovias não foram uma necessidade interna e consciente das regiőes do terceiro mundo, mas, foram-no do capitalismo, não só do capitalismo industrial inglês, mas (mais precisamente) do capitalismo financeiro. As garantias, no Brasil, do Estado Imperial, por si só já eram bastante alentadoras para se investir nos trópicos tupiniquins. Portanto, concluimos que esta é mais uma alienação dos téricos e pesquisadores da "Nova História Econômica". Metodologia cientifiça ou parcialidade ideológica?

(9) Idem, p. 19

(10) Idem, pp. 53.54. 